\title{
VIII. Description of a singular phenomenon in a thunder-cloud
}

\section{L.C. Lichtenberg}

To cite this article: L.C. Lichtenberg (1800) VIII. Description of a singular phenomenon in a thunder-cloud, Philosophical Magazine Series 1, 6:21, 41-42, DOI: 10.1080/14786440008677183

To link to this article: http://dx.doi.org/10.1080/14786440008677183

曲 Published online: 18 May 2009.

Submit your article to this journal $\sqsubset \pi$

Џ Article views: 3

Q View related articles $\sqsubset$ 
We wanted alfo fmall portable tables, and thefe C. Didot has undertaken. I have begun an edition of Logarithms carried to fix decimal places, like thofe given by myfelf and Lacaille in 1760 , which were publithed by Marie in 1768 , and reprinted four times afterwards, but ftill with more faults than the firft time. We at length, however, have a permanent edition, which it will not be neceflary to reprint every ten years with more errors than thofe before difcovered.

M. Bogdanich, affiftant at the obfervatory of Buda, has made, in feveral cities of Croatia, obfervations of great importance to Geography.

[To be concluded in the next Number.]

VIII. Deffription of a fingular Pbenoncnen in a TbunderCloud. By L. C. Lichtenterg**

$\mathrm{O}$

$\mathrm{N}$ a fummer's day, exceedingly hot and fultry, the barometer being at 27 inches feven lines, and Reaumur's thermometer at $22_{2}$, there was formed, about three in the afternoon, to the north of Gotha, a dark thunder-cloud, having the appearance of rocks piled upon each other, and in thape. almoft like a mufhroom. (Plate r. Yig. I.) The magnificent fpcotacle exhibited by this immenfe mafs floating in the blue expanfe of the atmofphere excited my attention; and I foon obferved, that, from the finall part which reprefented the ftem of the mulhroom, there arofe a fine bright vapour, which in a few moments formed a perfect ring around this part of the cloud. The ring feemed to be in violent agitation, by which it became always more enlarged, fo that in the courfe of a minute it exceeded the greatef breadth of the upper part of the cloud. It then began to extend itfelf upwards and downwards, and in lefs than thirty feconds the whole cloud was enveloped in a tranfparent covering, (Fig. 2.) This phenomenon had fcarcely continued a minute when the cloud began to extend itfelf, as if by a current of air forced from its interior, and to affume the form of a fan. It now loft its fmooth rim, which terminated, as it were, in fringes,

* From Magazin fur das Newefte ans de Phyll, Vol.I.

VOL, VI.

(x) 
and the whole acquired the form of a thunder-cloud. Some minutes after, black rainy clouds, formed of the vapour driven downwards, and of the remains of the covering, were collected below; and I expected every noment to fee the firft flafh of lightning, which foon followed. A little rain fell at fome diftance, but within a quarter of an hour the cloud was fo diftended that it was foon loft in a thin mift. The fame phenomenon, though not fo ftriking, I have fince feen in a great many other thunder-clouds, but inverted. Initead of a fine vapour being thrown out, and forming a covering, I faw white clouds fink down, fpread themfelves out like a veil over the arched part of the cloud, and difperfe themfelves in it. The reafon why the vapour thrown out from the cloud here defcribed formed a ring, was its fingular form. The vapour, by being forced out on all fides, was fo compreffed that it could extend itfelf only edgeways, and afterwards diffufe itfelf round the cloud.

If this phenomenon be compared with the electric experiment where a ball of cotton, fufpended by a filk thread, is introduced into a metal veffel of a cylindric form and fufficient width, and where the veffel is fometimes rendered electric and fometimes deprived of its electricity, the idea I mean to convey by this defcription will be readily conceived. I am of opinion that I can thercby prove that we might examine the electric ftate of the upper regions of the atmofphere, and even of the clouds, with accuracy, if the latter were obferved more frequently than has hitherto been done, and were they employed as natural electrometers for this purpofe.

IX. Offervations on the Elk. By the late E. H. SMITh, Pbysician*.

THE accounts hitherto publithed by Naturalifts, of the Elk and the Moofe, two very remarkable animals of the: deer kind, are confufed and unfatisfactory. Befide the mirapprehenfions which they contain relative to both animals, all the difficultics in the way of obtaining juft notions con-

* From the Anerician Medical Repofitory, Vol. II. No. 2. 